\title{
Maximising blackcurrant anthocyanins: Temporal changes during ripening and storage in different genotypes
}

\author{
Jordi Giné Bordonaba, Gemma A. Chope and Leon A. Terry* \\ Plant Science Laboratory, Cranfield University, Cranfield, UK
}

\begin{abstract}
Increasing evidence suggests that anthocyanins, as natural antioxidants, exert anti-carcinogenic, anti-inflammatory, vaso-protective and anti-obesity effects when tested in vitro or in vivo. Blackcurrant (Ribes nigrum L.) berries are a rich source of anthocyanins with concentrations up to 4-fold greater than that of other common fruits. However, there is a paucity of information on how blackcurrant anthocyanins change during ripening on the bush or during postharvest storage, which could lead to better selection of fruits with enhanced health-promoting properties. Accordingly, the present study describes the temporal changes in anthocyanins in different blackcurrant genotypes during the late stages of development or as a result of postharvest storage at different temperatures. In all cases, four major anthocyanins (viz. cyanidin-3-glucoside, cyanidin-3-rutinoside, delphinidin-3glucoside and delphinidin-3-rutinoside) were identified, accounting for over $80 \%$ of the total anthocyanin concentrations. Three different development stages (viz. early ripe (ER), fully ripe (FR) or over ripe (OR)) were chosen when fruit were at commercial maturity but presented different colorations. Anthocyanin concentration was nearly double in OR berries than ER, however the temporal changes during ripening were genotype-dependent, with some cultivars reaching maximum concentrations at the FR stage. During postharvest storage anthocyanin synthesis was observed in both ER and FR berries during storage, but ER berries never reached the concentrations of those harvested at FR stage. Storage temperature crucially affected anthocyanin concentrations in FR but not in ER berries. The results from this study may provide both growers and industry with additional information for maximising anthocyanin concentrations in blackcurrant berries.
\end{abstract}

Keywords: Maturity, Ribes nigrum L., temperature

\section{Introduction}

The blackcurrant (Ribes nigrum L.) is a species of currant with dark purple coloration and which is increasing in popularity in Europe. Even though the market for fresh blackcurrants seems to be growing, most of the blackcurrants produced are distributed as frozen and thermally processed products [3, 4, 21]. Among the compounds responsible for the characteristic colour of blackcurrant fruits are the polyphenolic compounds and more specifically the highly coloured flavonoid type anthocyanins (Fig. 1). Research over the last decade have demonstrated berries, including blackcurrants, to be one of the richest sources of anthocyanins with concentrations up to $4 \mathrm{mg} \mathrm{g}^{-1}$ of fresh weight [2, 8]. Increasing interest in the anthocyanin concentration of several berries is, however, not only due to their potential as natural colorants but also to their associated health-promoting properties. Despite the enormous variability between individuals, consumption of anthocyanins was recently estimated as $12.5 \mathrm{mg} \mathrm{day}^{-1}$ per person in the USA [11, 20], or even greater in Europe [1]. To date, and in spite of their poor bioavailability [13], evidence suggests that anthocyanins,

*Corresponding author: Leon A. Terry, Plant Science Laboratory, Cranfield University, Cranfield MK43 0AL, UK. Tel.: +44 7500 766490; E-mail: 1.a.terry@cranfield.ac.uk. 


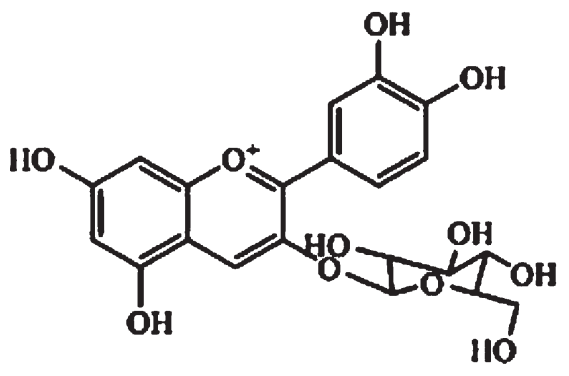

1<smiles>OCC1(O)C(O)=CC(O)=C2C=[O+]c3cc(-c4cc(O)c(O)c(O)c4)cc(O)c3OC1=C2</smiles>

3

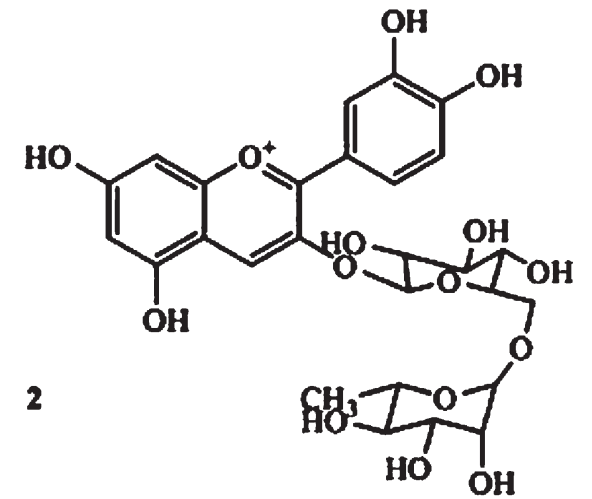

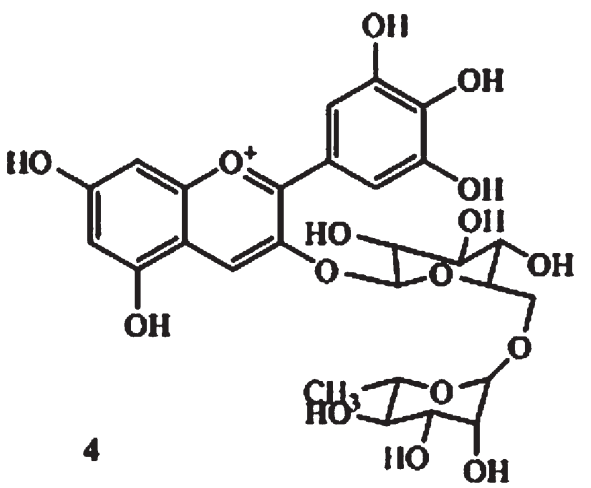

Fig. 1. Chemical structure of main anthocyanins found in blackcurrant berries: (1) Cyanidin-3-glucoside; (2) Cyanidin-3-rutinoside; (3) Delphinidin-3-glucoside and (4) Delphinidin-3-rutinoside.

as natural antioxidants, exert anti-carcinogenic, anti-inflamatory, vaso-protective and anti-obesity effects when tested in vitro or in vivo [13]. Nevertheless, the bioavailability of these compounds seems to be structurally-dependent since plasma concentrations relative to the blackcurrant dose received was greater for rutinosides than glucosides in both rabbits and humans [13].

Anthocyanin concentrations in berries and other fruits are known to be affected by several preharvest (viz. genotype, maturity at harvest, agroclimatic factors $[8,16,17,18,21]$ ) and postharvest (viz. storage period, storage temperature $[6,17]$, etc.) conditions. For instance, anthocyanin accumulation takes place mainly during the later stages of berry ripening [5, 16]. This said, only one study has quantified anthocyanin changes during blackcurrant development [16]. Similarly, anthocyanin changes during storage occur in a temperature and time dependent manner for many berry fruits. In raspberries, for instance, fruits stored at $0{ }^{\circ} \mathrm{C}$ for 24 days contained $70 \%$ more anthocyanins as compared to initial values after harvest [15]. Overall, there is a noticeable paucity of information on how blackcurrant anthocyanins change during ripening on the bush or during postharvest storage, which could lead to better selection of fruits with enhanced health-promoting properties. Accordingly, the present study describes the temporal changes in anthocyanins in three different blackcurrant genotypes during the late stages of development, yet when berries were at commercial maturity, or as a result of postharvest storage at different temperatures in cultivar Ben Hope.

\section{Materials and methods}

\subsection{Plant materials}

Blackcurrants (cvs. Ben Dorain, Ben Hope, Ben Gairn and Ben Tirran) were supplied by GlaxoSmithKline Plc. All berries were grown on the same farm in Norfolk, UK $\left(52^{\circ} 39^{\prime} \mathrm{N}, 0^{\circ} 54^{\prime} \mathrm{E}\right)$ during 2007 using conventional methods 
(Rob A. Saunders, pers. comm.) and harvested by hand at two or three different maturities; early ripe (ER), fully ripe (FR) or over ripe (OR) based on standard commercial evaluation. Samples of the three cultivars were harvested on different dates reflecting the time course variability of each cultivar. After harvest, samples were transported over ice (but were not allowed to freeze) to Cranfield University, arriving within $4 \mathrm{~h}$ of harvest.

\subsection{Experimental design}

Experiment I - 'anthocyanin changes during berry ripening': Berries from cvs. Ben Dorain, Ben Gairn and Ben Tirran were used to monitor the temporal changes in anthocyanin concentrations when fruits were at commercial maturity but presented different colorations (ER, FR and OR based on 90, 95 and 100\% of black coloration, respectively) and total soluble solids (TSS; ${ }^{\circ}$ Brix).

Experiment II - 'anthocyanin changes during postharvest storage at different temperatures': In order to investigate the effect of temperature during postharvest storage of blackcurrant berries, a temperature gradient was set up, consisting of a bespoke solid aluminium block $(86.0 \mathrm{~cm} \times 20.2 \mathrm{~cm} \times 10.0 \mathrm{~cm})$ with 5 rows of 20 precision-drilled holes of $2.5 \mathrm{~cm}$ diameter and $7 \mathrm{~cm}$ depth, with sufficient metal between each hole $(1 \mathrm{~cm})$ to ensure adequate heat and/or cold transfer along the block [7]. The temperature gradient was measured using a digital thermometer (Jenway, Essex, UK) and was set at $20^{\circ} \mathrm{C}$ at one end of the block and $1^{\circ} \mathrm{C}$ at the other end, resulting in increments of $1^{\circ} \mathrm{C}$. Blackcurrant berries from cv. Ben Hope ( $c a .12 \mathrm{~g}$ ) were placed in glass vials within each hole. Where possible, fruit were left as racemes, with individual berries added to make up the total mass. The experiment was repeated on two separate occasions corresponding to ER and FR harvested berries.

\subsection{Anthocyanins extraction and quantification}

Based on earlier works $[7,8,18]$ individual anthocyanins from blackcurrant berries were extracted by mixing freeze-dried sample $(150 \mathrm{mg})$ with $3 \mathrm{ml}$ of HPLC grade methanol: $\mathrm{HCl}$ : Water (70: 0.5: 29.5; v/v/v). Vials of the slurry were then held at $35^{\circ} \mathrm{C}$ for $1.5 \mathrm{~h}$ in a shaking water bath, mixing the samples every $15 \mathrm{~min}$. Finally, the sample was filtered though a $0.2 \mu \mathrm{m}$ Millex-GV syringe driven filter.

The anthocyanin profile of blackcurrant extracts was determined according to [8] with some modifications to achieve superior peak separation and resolution. The HPLC system comprised an Agilent 1200 series HPLC system (Agilent, Berks., UK), equipped with an Agilent 1200s DA G1315B/G1365B photodiode array with multiple wavelength detector. Blackcurrant extracts $(20 \mu \mathrm{l})$ were injected into a Zorbax Eclipse XDB-C18 column of $250 \mathrm{~mm} \times 4.6 \mathrm{~mm}$ diameter, $5 \mu \mathrm{m}$ particle size with an XDB-C18 guard column of $12.5 \mathrm{~mm} \times 4.6 \mathrm{~mm}$ diameter (Agilent). The mobile phase consisted of degassed 2.5\% (v/v) acetonitrile and 5\% (v/v) formic acid in HPLCgrade water (A) and acetonitrile (B) following a linear gradient program of increasing polarity in several steps (from 0 to $13 \% \mathrm{~B}$ in $10 \mathrm{~min}, 18.7 \mathrm{~min}-18 \% \mathrm{~B}, 22 \mathrm{~min}-65 \% \mathrm{~B}$ and $27 \mathrm{~min}-65 \% \mathrm{~B}$ ). The flow rate was $1 \mathrm{ml}$ $\mathrm{min}^{-1}$ and the column temperature was set at $40^{\circ} \mathrm{C}$ (Agilent 1200s, G1316A, Berks., UK). Anthocyanins were detected at $520 \mathrm{~nm}$ and the presence and abundance of each anthocyanin was calculated by comparing the peak area with external standards (delphinidin-3-glucoside (delp-3-gluc), cyanidin-3-glucoside (cya-3-gluc) and cyanidin-3rutinoside (cya-3-rut)) (Extrasynthèse, Genay, France) using Agilent ChemStation Rev. B.02.01. The concentration of delphinidin-3-rutinoside (delp-3-rut) was estimated from the calibration curve of delphinidin-3-glucoside [8]. Similarly, the concentrations of unidentified peaks were calculated from the calibration curve of cyanidin-3-glucoside.

\subsection{Statistical analysis}

All statistical analyses were carried out using Genstat for Windows Version 12.1.0.3338 (VSN International Ltd, Herts., UK). Data were subjected to analysis of variance tests. Least significant difference values (LSD; $p=0.05)$ were calculated for mean separation using critical values of $t$ for two-tailed tests. Analysis was performed on the concentrations of the analytes on a fresh weight $(\mathrm{FW})$ basis. 


\section{Results and discussion}

\subsection{Anthocyanin changes during berry ripening}

The anthocyanins profile of blackcurrants is well known. The four major anthocyanins (viz. delp-3-gluc, delp3-rut, cya-3-gluc and cya-3-rut) were first reported by Chandler and Harper in 1958 [6]. Since then, numerous studies have identified these compounds in different blackcurrant genotypes or blackcurrant-based products [2,8]. In agreement with previous work, the aforementioned major anthocyanins accounted for over $80 \%$ of the total anthocyanin concentration and were identified and quantified according to their retention time, UV-Vis spectra and comparison with standards. Other minor anthocyanins were also observed in all the genotypes analysed. For instance, the chromatographic profile of berries from cv. Ben. Tirran clearly revealed eight different peaks as compared to six peaks observed in the other cvs. investigated (Fig. 2). Although variations may exist between genotypes, blackcurrant berries tend to ripen over a 2 week period. In the present study, berries were harvested based on commercial evaluation and therefore reflect the beginning (ER), middle (FR) and end of the period (OR), where most berries can be harvested for commercial purposes (based on colour and TSS ( ${ }^{\circ}$ Brix) values). On a FW basis (Fig. 3), individual anthocyanin concentrations significantly differed between genotypes and degrees of maturity. Individual anthocyanin concentration increased gradually as fruit ripened for all the cultivars investigated which was in agreement with earlier works on blackcurrants [16] and other berry fruits [5]. This said, similar amounts were recorded for FR or OR berries from cv. Ben Dorain. The relative concentration of each individual anthocyanin remained fairly constant regardless of fruit development stage, except for cv. Ben Gairn where OR fruits had three times as much anthocyanin glucosides
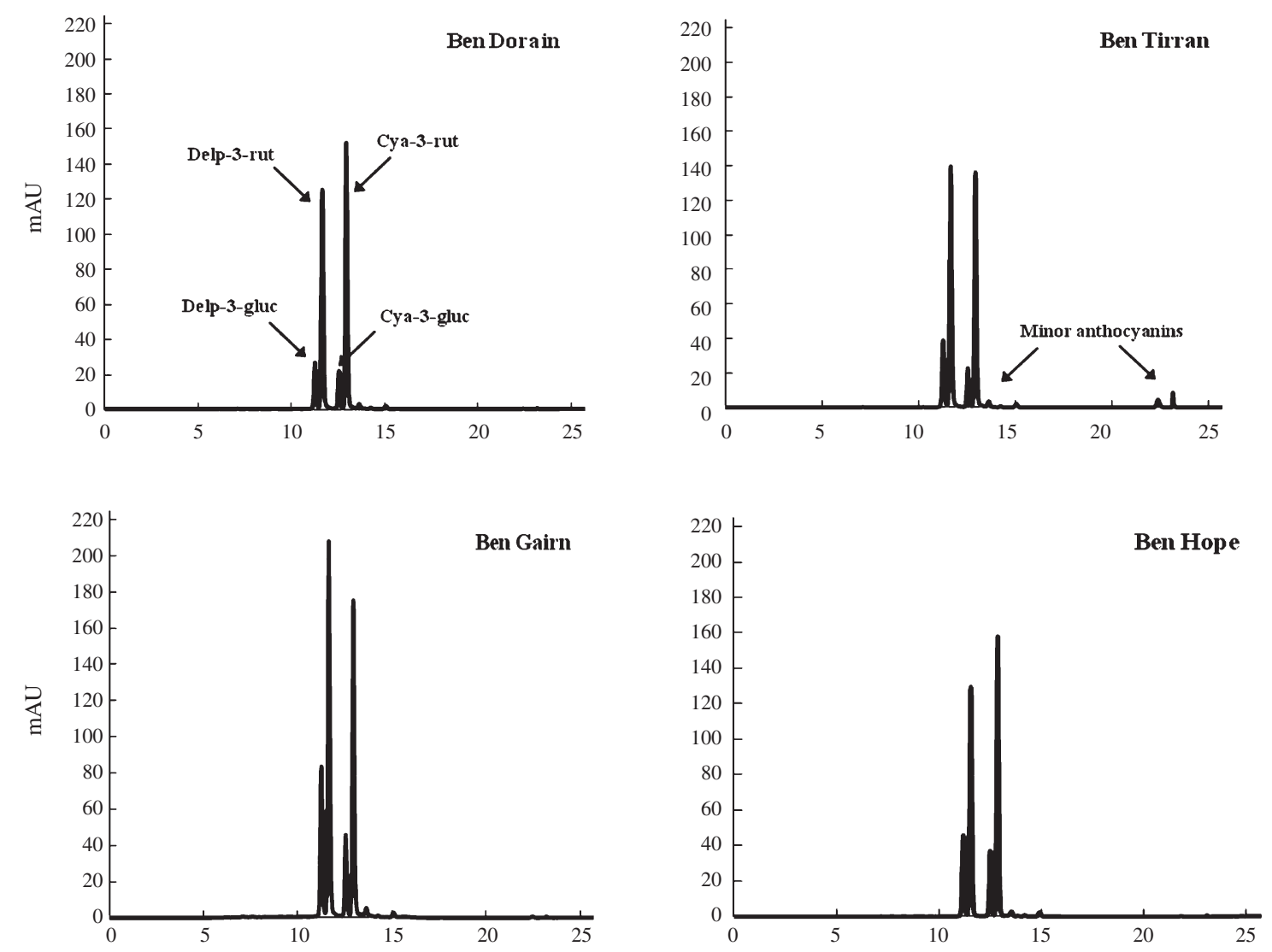

Fig. 2. Chromatographic profile of anthocyanins found in fully ripe blackcurrant berries from different cultivars (viz. cya-3-gluc (peak 3), cya-3-rut (peak 4), delp-3-gluc (peak 1),delp-3-rut (peak 2)). 


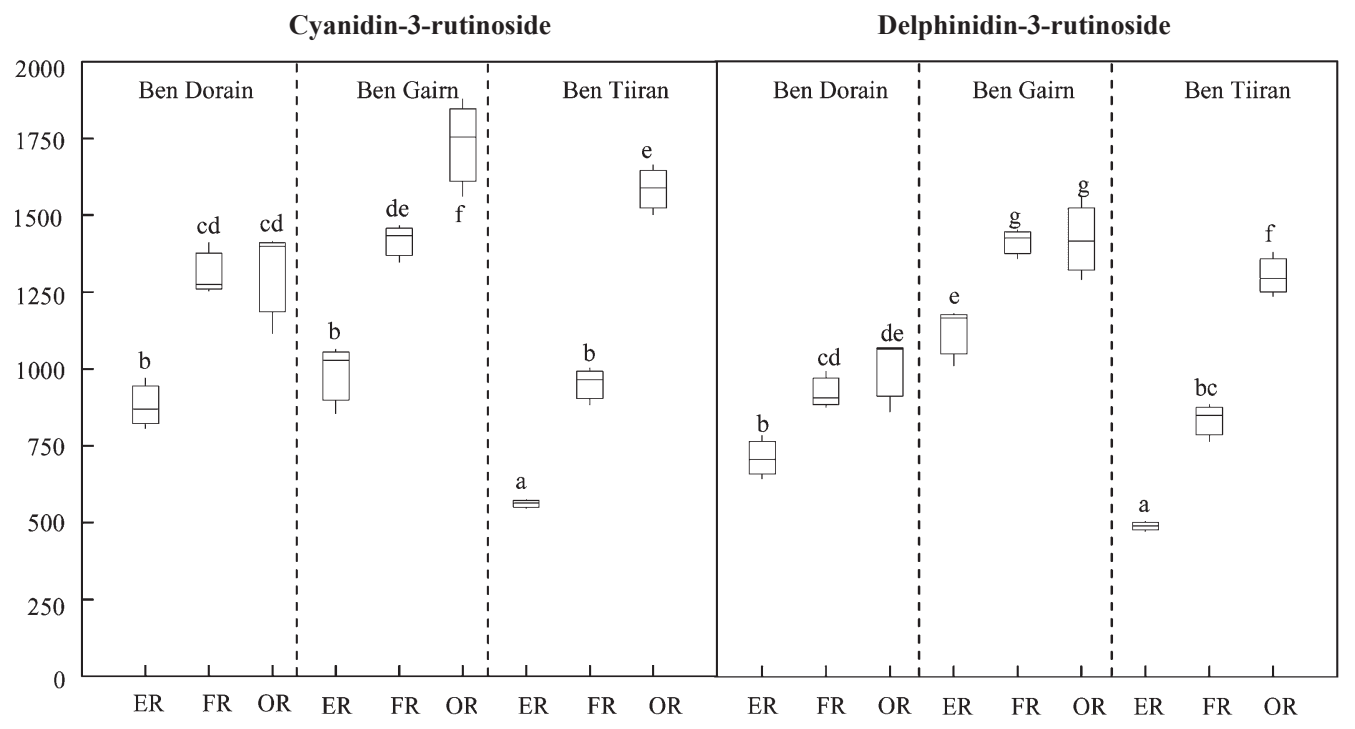

Cyanidin-3-glucoside

Delphinidin-3-glucoside

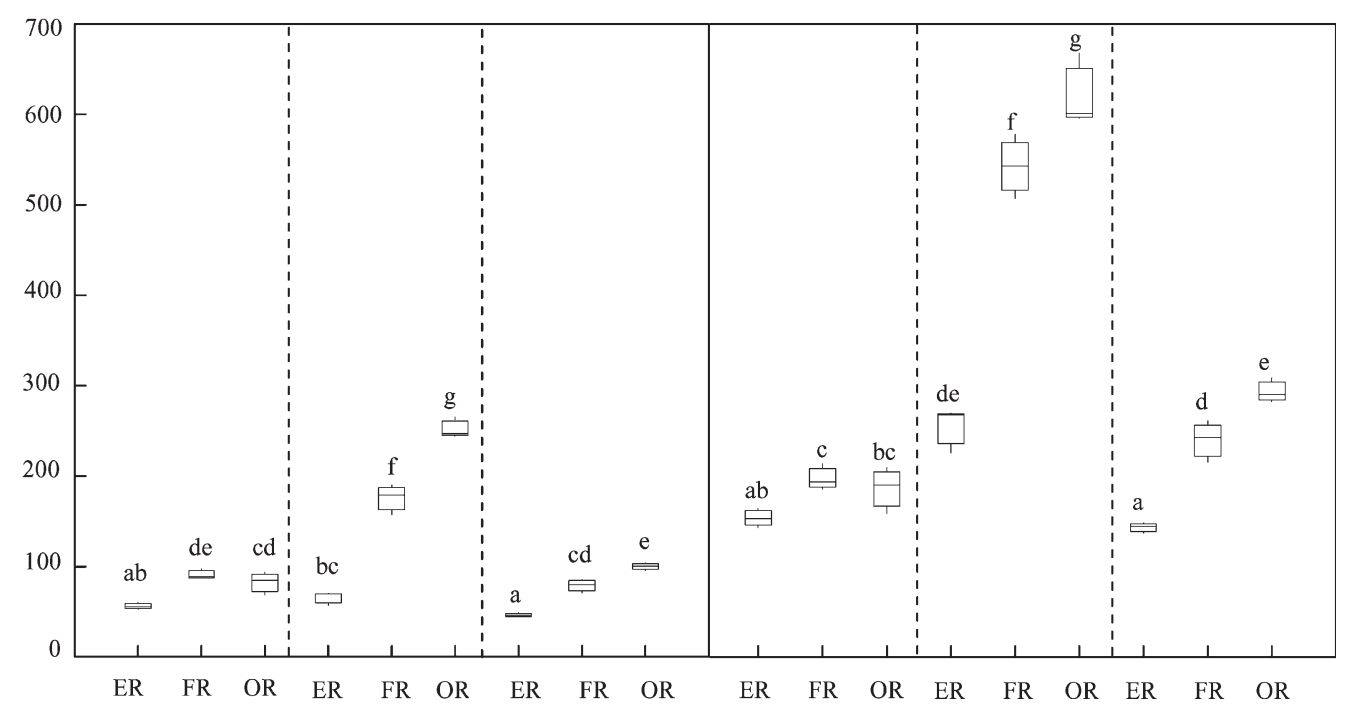

Fig. 3. Accumulation patterns of individual anthocyanins ( $\left.\mu \mathrm{g} \mathrm{g}^{-1} \mathrm{FW}\right)$ through different development stages (viz. early ripe (ER), fully ripe (FR) and over ripe $(\mathrm{OR}))$ in different blackcurrant cultivars. Letters indicate significant differences between means $(p<0.05)$.

than the other cultivars investigated (Fig. 3). These results suggest that the optimum time to harvest in terms of the anthocyanin content is at the OR stage, and that within the relatively short window of commercial maturity there are large variations in the concentrations of health-promoting properties of the berries.

\subsection{Anthocyanin changes during postharvest storage at different temperatures}

Only berries from cv. Ben Hope, harvested at two different maturities, were used to monitor anthocyanin changes during postharvest storage (Experiment II). As observed for other cultivars, the total anthocyanin concentration from cv. Ben Hope was greater in FR ( $\left.3538 \mu \mathrm{g} \mathrm{g}^{-1} \mathrm{FW}\right)$ compared to ER $\left(1412 \mu \mathrm{g} \mathrm{g}^{-1} \mathrm{FW}\right)$ blackcurrants. The observed differences in the individual anthocyanin content between berries harvested at different maturity stages persisted throughout the 7-day duration of the storage trial (Table 1). 
Table 1

Changes in concentrations of individual anthocyanins $\left(\mu \mathrm{g} \mathrm{g}^{-1} \mathrm{FW}\right)$ in blackcurrant berries (cultivar Ben Hope) harvested at early ripe (ER) or fully ripe (FR) maturity stage and stored for 7 days at different temperatures. LSD values $(p<0.05)$ are given for the interaction of time* temperature* maturity for each individual anthocyanin

\begin{tabular}{|c|c|c|c|c|c|c|}
\hline \multirow[t]{2}{*}{ Maturity } & \multirow[t]{2}{*}{ Day } & \multicolumn{5}{|c|}{ Storage temperature } \\
\hline & & $20-17^{\circ} \mathrm{C}$ & $16-13^{\circ} \mathrm{C}$ & $12-9^{\circ} \mathrm{C}$ & $8-5^{\circ} \mathrm{C}$ & $4-1^{\circ} \mathrm{C}$ \\
\hline \multicolumn{7}{|c|}{ Cya-3-gluc $(\mathrm{LSD}=45.4)$} \\
\hline & $0^{*}$ & - & - & - & 113 & - \\
\hline & 1 & 142 & 135 & 128 & 128 & 128 \\
\hline & 3 & 157 & 160 & 146 & 131 & 139 \\
\hline \multirow[t]{4}{*}{ ER } & 7 & 223 & 230 & 258 & 179 & 157 \\
\hline & $0^{*}$ & - & - & - & 198 & - \\
\hline & 1 & 240 & 191 & 191 & 188 & 172 \\
\hline & 3 & 243 & 248 & 237 & 179 & 230 \\
\hline FR & 7 & 174 & 163 & 178 & 192 & 179 \\
\hline \multicolumn{7}{|c|}{ Cya-3-rut $(\mathrm{LSD}=311.3)$} \\
\hline & $0^{*}$ & - & - & - & 692 & - \\
\hline & 1 & 783 & 759 & 744 & 782 & 799 \\
\hline & 3 & 1009 & 918 & 825 & 787 & 888 \\
\hline \multirow[t]{4}{*}{ ER } & 7 & 1427 & 1409 & 1387 & 1126 & 1100 \\
\hline & $0^{*}$ & - & - & - & 1789 & - \\
\hline & 1 & 2240 & 1900 & 1902 & 1698 & 1668 \\
\hline & 3 & 1177 & 1265 & 1568 & 1721 & 2006 \\
\hline FR & 7 & 1851 & 1939 & 2398 & 2612 & 1641 \\
\hline \multicolumn{7}{|c|}{ Delp-3-gluc (LSD = 69.0) } \\
\hline & $0^{*}$ & - & - & - & 172 & - \\
\hline & 1 & 229 & 211 & 195 & 195 & 195 \\
\hline & 3 & 264 & 242 & 220 & 196 & 209 \\
\hline \multirow[t]{4}{*}{ ER } & 7 & 362 & 325 & 322 & 237 & 236 \\
\hline & $0^{*}$ & - & - & - & 321 & - \\
\hline & 1 & 395 & 309 & 307 & 296 & 321 \\
\hline & 3 & 215 & 226 & 196 & 123 & 344 \\
\hline FR & 7 & 347 & 320 & 299 & 311 & 315 \\
\hline \multicolumn{7}{|c|}{ Delp-3-rut $(\mathrm{LSD}=195.7)$} \\
\hline & $0^{*}$ & - & - & - & 434 & - \\
\hline & 1 & 516 & 485 & 466 & 507 & 502 \\
\hline & 3 & 674 & 595 & 509 & 479 & 551 \\
\hline \multirow[t]{4}{*}{ ER } & 7 & 932 & 834 & 749 & 623 & 670 \\
\hline & $0^{*}$ & - & - & - & 1229 & - \\
\hline & 1 & 1532 & 1299 & 1275 & 1118 & 1204 \\
\hline & 3 & 824 & 902 & 1138 & 1311 & 1411 \\
\hline FR & 7 & 1366 & 1288 & 1127 & 1158 & 1142 \\
\hline
\end{tabular}

*Values at day 0 correspond to anthocyanin concentration measured in blackcurrant berries kept at $5 \pm 1{ }^{\circ} \mathrm{C}$ before the start of the storage trial.

The concentration of cya-3-gluc was greater at temperatures above $12^{\circ} \mathrm{C}$ in both ER and FR berries. There was no effect of temperature on the concentration of cya-3-rut or delp-3-gluc in ER berries, but in FR berries, cya-3-rut and delp-3-gluc concentration was greatest when berries were stored between $5-12^{\circ} \mathrm{C}$ (Table 1). The concentration of delp-3-rut was not affected by temperature, which may reflect the higher stability of this anthocyanin as compared to the other anthocyanins present in blackcurrant fruits. Similar findings were observed by Brennan et al. (1997) [4], 
who reported the greater stability of delphinidins in blackcurrant juice. It is commonly accepted that darkening of the berries usually occurs during storage or during the latest stages of berry development. During postharvest storage, such change in coloration occurs in a temperature- and time-dependent manner, and has been mainly associated with an increase in anthocyanin concentrations [9, 15]. Anthocyanin synthesis was observed in both ER and FR berries during storage; this said, the anthocyanin concentrations in ER berries never reached levels equal to those in berries harvested at FR stage. Similarly, it has been reported that highbush blueberries harvested at earlier stages of development never attained the same anthocyanin concentration and colour as that of fully ripe fruit [10]. The observed higher total anthocyanin concentrations observed in berries stored at higher temperatures may be the result of increased metabolic activity which occurs at higher temperatures leading to greater oxidative stress (i.e. generation of radical species), and hence perhaps a greater requirement for antioxidants within the fruit.

Increasing evidence suggests that anthocyanins, as natural antioxidants, exert a wide range of health-promoting properties (viz. anti-carcinogenic, anti-inflamatory, vaso-protective and anti-obesity) when tested in vitro or in vivo [14]. Anthocyanins detected in human urine following ingestion of blackcurrant juice accounted for only $0.026-0.050 \%$ of the total amount ingested [12]. The plasma concentration relative to the dose received was greater for rutinosides than glucosides in both rabbits and humans [13], indicating that they were more bioavailable. These findings suggest that although total anthocyanins were present in lower concentrations in ER blackcurrants (Table 1 Fig. 3), as was also observed by Wang et al. [19] in raspberries and Shin et al. [18] in strawberries, proportionally they contained greater amounts of the more bioavailable rutinosides, which could compensate for the lower overall amount.

\section{Conclusions}

The temporal variations in blackcurrant anthocyanins during storage at different temperatures are strongly influenced by the maturity of the berries at harvest. When berries were harvested at the ER stage, they did not attain the anthocyanin concentrations of those harvested at the FR stage regardless of cultivar or storage temperature and time. No other studies thus far have studied in detail the temporal changes in anthocyanin concentrations during berry development or as a result of postharvest storage. Hence, results from this study may assist growers and industry on selecting optimum maturity at harvest (FR or OR berries) and best storage conditions required to maximize the quality of blackcurrant berries, specially addressing individual requirements for each of the different blackcurrant-based products available in the market.

\section{Acknowledgements}

The authors thank the Horticultural Development Company (HDC; CP_43) and GlaxoSmithKline Plc (GSK) for financial support. Mr. Rob Saunders (GSK) is thanked for supplying the fruit. All Plant Science Laboratory staff and students are thanked for their kind assistance, especially Mrs. Balwinder Cook for her help and advice with HPLC.

\section{References}

[1] $\varnothing$. Andersen, Anthocyanins, in: Encyclopedia of Life Sciences, John Wiley \& Sons, Ltd., Chichester, 2002.

[2] M.J. Anttonen and R.O. Karjalainen, High performance liquid chromatography analysis of black currant (Ribes nigrum L.) fruit phenolics grown either conventionally or organically, Journal of Agricultural and Food Chemistry 54 (2006), 7530-7538.

[3] R. Brennan, Currant and gooseberries (Ribes L.), in: The Encyclopaedia of Fruit and Nut Crops, J. Janick, CABI Inc., New York, 2005, pp. 191-295.

[4] R.M. Brennan, E.A. Hunter and D. Donald Muir, Genotypic effects on sensory quality of blackcurrant juice using descriptive sensory profiling, Food Research International 30 (1997), 381-390.

[5] F. Carbone, A. Preuss, R.C.H. De Vos, E. D’Amico, G. Perrotta, A.G. Bovy and C. Rosati, Developmental, genetic and environmental factors affect the expression of flavonoid genes, enzymes and metabolites in strawberry fruits, Plant Cell and Environment 32 (2009), $1117-1131$. 
[6] B.V. Chandler and K.A. Harper, Anthocyanins in blackcurrant fruits, Nature 181 (1958), 131-132.

[7] G.A. Chope, J. Giné Bordonaba and L.A. Terry, Maturity at harvest determines quality and nutritional value of blackcurrant berries stored under different conditions using a bespoke temperature block. Journal of Horticultural Sciences and Biotechnology (submitted).

[8] J. Giné Bordonaba and L.A. Terry, Biochemical profiling and chemometric analysis of seventeen UK-grown black currant cultivars, Journal of Agricultural and Food Chemistry 56 (2008), 7422-7430.

[9] W. Kalt, C.F. Forney, A. Martin and R.L. Prior, Antioxidant capacity, vitamin C, phenolics, and anthocyanins after fresh storage of small fruits. Journal of Agricultural and Food Chemistry 47 (1999), 4638-4644.

[10] W. Kalt, C. Lawand, D.A.J. Ryan, J.E. McDonald, H. Donner and C.F. Forney, Oxygen radical absorbing capacity, anthocyanin and phenolic content of highbush blueberries (Vaccinium corymbosum L.) during ripening and storage, Journal of the American Society for Horticultural Science 128 (2003), 917-923.

[11] T.K. McGhie and M.C. Walton, The bioavailability and absorption of anthocyanins: Towards a better understanding, Molecular Nutrition \& Food Research 51 (2007), 702-713.

[12] M. Netzel, G. Strass, M. Janssen, I. Bitsch and R. Bitsch, Bioactive anthocyanins detected in human urine after ingestion of blackcurrant juice, Journal of Environmental Pathology, Toxicology and Oncology 20 (2001), 89-95.

[13] I.L.F. Nielsen, L.O. Dragsted, G. Ravn-Haren, R. Freese and S.E. Rasmussen, Absorption and excretion of black currant anthocyanins in humans and watanabe heritable hyperlipidemic rabbits, Journal of Agricultural and Food Chemistry 51 (2003), $2813-2820$.

[14] R.L. Prior, Absorption and metabolism of anthocyanins: Potential health effects, in: Phytochemicals: Mechanisms of Action, M.S. Meskin, W.R. Bidlack and A.J. Davies, ed., CRC, Boca Raton, FL, 2004, pp. 1-19.

[15] J. Robbins, T.M. Sjulin and M. Patterson, Postharvest storage characteristics and respiration rates in five cultivars of red raspberry, HortScience 24 (1989), 980-982.

[16] M. Rubinskiene, P. Viskelis, I. Jasutiene, P. Duchovskis and C. Bobinas, Changes in biologically active constituents during ripening in black currants, Journal of Fruit and Ornamental Plant Research 14 (2006), 237-246.

[17] Y. Shin, J.A. Ryu, R.H. Liu, J.F. Nock and C.B. Watkins, Harvest maturity, storage temperature and relative humidity affect fruit quality, antioxidant contents and activity, and inhibition of cell proliferation of strawberry fruit, Postharvest Biology and Technology 49 (2008), 201-209.

[18] L.A. Terry, G.A. Chope and J. Giné Bordonaba, Effect of water deficit irrigation and inoculation with Botrytis cinerea on strawberry (Fragaria $\times$ ananassa) fruit quality, Journal of Agricultural and Food Chemistry 55 (2007), 10812-10819.

[19] S.Y. Wang, C.T. Chen and C.Y. Wang, The influence of light and maturity on fruit quality and flavonoid content of red raspberries, Food Chemistry 112 (2009), 676-684.

[20] X. Wu, G.R. Beecher, J.M. Holden, D.B. Haytowitz, S.E. Gebhardt and R.L. Prior, Concentrations of anthocyanins in common foods in the United States and estimation of normal consumption, Journal of Agricultural and Food Chemistry 54 (2006), $4069-4075$.

[21] J. Zheng, B. Yang, S. Tuomasjukka, S. Ou and H. Kallio, Effects of latitude and weather conditions on contents of sugars, fruit acids, and ascorbic acid in black currant (Ribes nigrum L.) juice, Journal of Agricultural and Food Chemistry 57 (2009), $2977-2987$. 